\title{
The effect of quality attributes in determination of price for plantation-grown Teak (Tectona grandis) logs in Sri Lanka
}

\author{
J.K.P.C. Jayawardhane, P.K.P. Perera, R.S. Lokupitiya, H.S. Amarasekara, \\ N. Ruwanpathirana
}

Jayawardhane J.K.P.C., Perera P.K.P., Lokupitiya R.S., Amarasekara H.S., Ruwanpathirana N., 2016. The effect of quality attributes in determination of price for plantation-grown Teak (Tectona grandis) logs in Sri Lanka. Ann. For. Res. 59(1): 105-116.

Abstract. Teak (Tectona grandis) is one of the highly demanded timber species in Sri Lanka. When buying teak $\log$, customers assess their quality by visual appraisal of surface characteristics such as visible defects. Hence, the buyers' preference for logs with desired attributes is reflected by the price achieved in the market. In this study, we examined the influence of visually observable quality attributes of plantation grown teak logs on their market price. A set of 650 randomly selected teak logs were assessed for dimensions, shape defects, surface defects and end-defects. Length of the log, mid-circumference (under bark), diameter at top-end and butt-end, number of knots per meter, average diameter of the knots, bend fraction, percentage of heartwood, shape of the log, presence of buttress, position of the hollows, presence of felling damages, splits and heart rot were recorded using standard methods. Selling prices of $\log$ s were obtained from the records of $\log$ storing facilities. By using the multiple linear regressions, a price-quality model was developed to explain the impact of quality attributes on selling price. The regression model achieved a strong coefficient of determination $\left(R^{2}\right)$ of 0.87 . Accordingly, the length, mid-circumference, number of knots per meter, bend fraction, hollow position, presence of buttresses and presence of heart rot were found to have a significant influence on the price. The relative price reduction due to presence of a specific log defect was further examined using the derived price-quality model. The presence of high number of knots had the highest detrimental impact on price, followed by the higher bend fraction, presence of hollows at top end and/or middle of the log, presence of heart rot and presence of buttresses respectively. These findings have implications in the improved management of teak plantations. Keywords wood quality attributes, timber defects, buyers' preference, hedonic pricing, price-quality model

Authors. J.K.P.C. Jayawardhane, P.K.P. Perera (priyan@sjp.ac.lk), R.S. Lokupitiya, H.S. Amarasekara - Department of Forestry and Environmental Sciences, University of Sri Jayewardenepura, Nugegoda, Sri Lanka; R.S. Lokupitiya Department of Statistics, University of Sri Jayewardenepura, Nugegoda, Sri Lanka; N. Ruwanpathirana - State Timber Corporation, Sri Lanka. 
Manuscript received March 16, 2015; revised June 30, 2015; accepted August 24, 2015; online first September 7, 2015.

\section{Introduction}

The increasing population coupled with a steady economic development in Sri Lanka has created a substantial growth in demand for timber. According to recent studies, the current annual timber consumption in Sri Lanka is 1.6 million $\mathrm{m}^{3}$ from which, around $10 \%$ is supplied by imports (Ruwanpathirana 2014). Unlike in the past, the timber supply from natural forests has become limited with diminishing natural forest cover and restrictions on harvesting and transportation of timber (Amarasekara 1997). As such, the forest plantations have become an important source of timber at present. With both government and private sectors showing a growing interest in commercial forestry, the extent of forest plantations in the country has gradually increased over the past few decades. Recent reports further indicate that private sector investments in commercial forestry are likely to continue (Perera et al. 2006).

The Sri Lankan grown teak (Tectona grandis) has been identified as a highly durable timber with moderate level of workability, and recommended for end uses such as high quality furniture, wall paneling and medium sized constructions (Amarasekera 1996, Ruwanpathirana 2014). Teak has become one of the most popular timbers in Sri Lanka, especially for indoor furniture manufacturing and other interior applications owing to its inherent properties such as the unique colour and grain pattern which is known to vary with the provenance (Weerasinghe 2009). The demand and the price of teak logs vary with its quality. Hence, the log quality attributes are key determinants in defining prices and limits for timber utilization (Knoke et al. 2006).

When purchasing logs, a greater emphasis is placed on the lumber recovery potential from sawn logs. According to Gligoraş and Borz
(2015), the lumber recovery rate depends on the sawn wood species and the log volume, while the effective time consumption for sawing a log is mostly affected by number of cuts, log length and log volume. As such, the log length and its circumference inevitably become key considerations in customer's purchasing decision. Furthermore, other studies have identified the stem shape defects as the major group of visible stem defects affecting the sawn timber recovery (Riekkinen et al. 2004, Ivković et al. 2007, Thulasidas \& Bhat 2009). Customers assess log quality mainly by visually inspecting the characteristics of logs such as the log dimensions and visible defects with a prior knowledge of the intended end-use. In other words, the customer uses the "external appearance" of a $\log$ as an indicator of its quality. Therefore, the ultimate achievable price of a log will depend on its perceived quality, determined by the visual appraisal of observable quality attributes of the log (i.e. the achieved $\log$ price is a function of visually observable $\log$ quality attributes). This also provides the rationale for saw log grading where the logs are sorted based on dimensions and quality, in order to fit each individual log to the right enduse at a fair price.

In Sri Lanka, presently, the market receives teak logs of varying quality from numerous sources including the state and private plantations, as well as the home gardens. Over the years, the supply of high-quality teak logs has decreased while the demand and price have increased. The present competitive market conditions also pinpoint defects in logs previously not considered seriously. Aesthetic properties such as colour, knottiness, texture and stippling have become more desired in addition to other quality attributes in evaluating timber (Riekkinen et al. 2004, Chernyh et al. 2013). Meanwhile, the investments in commercial forest plantations by the private sector are also on 
the rise, and these private forest plantations are likely to become a significant source of teak logs in the supply chain of the local markets in the near future (Perera et al. 2012). Due to the growing heterogeneity of timber sources, the materials, and the end-uses, the identification of $\log$ qualities that significantly influence the achievable price in the market has become imperative from both, the lumber marketing and forest management perspectives.

In theory, the price of a specific good should increase with the growing demand. However, the consumer preferences are often depending on the qualities of goods which are eventually controlled by the properties of goods (Knoke et al. 2006). In the context of Sri Lankan grown teak, the past research has predominantly focused on the variation of mechanical and strength properties of timber in relation to silvicultural effects and provenances (Amarasekera 1996, Weerasinghe 2009, Perera et al. 2012). On the other hand, the marketing aspects and the customer preferences for teak timber in general, have received scant academic attention. Hence, there is a general lack of information on the impact of various $\log$ quality attributes on the selling price. Such information is highly important in improving the financial returns of teak management in Sri Lanka.

To bridge the information gap mentioned above, this study was designed to identify the key determinants of selling price of plantation-grown teak logs with respect to visual log quality attributes. The objectives of this study were to measure the log dimensions, shape defects, surface defects and end defects of teak logs according to the standard methods and to determine their influence on the timber buyers' preferences and achieved price during a typical auction process. The result of this study was concretized in a price-quality model for teak logs that ranks the importance of visual quality attributes.

\section{Materials and Methods}

\section{Study sites and sampling}

This study evaluated the log quality attributes of teak logs available at two state-owned (State Timber Corporation) log storing facilities (Egoda Uyana: $6^{\circ} 44.463{ }^{\prime} \mathrm{N}, 79^{\circ} 53.575^{\prime} \mathrm{E}$ and Kaldemulla: $6^{\circ} 48.322^{\prime} \mathrm{N}, 79^{\circ} 52.676^{\prime} \mathrm{E}$ ) in Colombo District, Sri Lanka. The State Timber Corporation holds the monopoly in harvesting and selling the logs from government forest plantations. The two storing facilities receive logs from all the teak planting regions of the country. The logs are sorted at the storing facilities and a price is assigned based on their volume and the current market value of teak timber, which is referred to as the "advertised price" in this study. Subsequently, the logs are sold at the advertised price or through an auctioning process where logs ultimately archive a "selling price" after advertised prices is further bargained by customers. In this study, a total of 650 randomly selected logs representing a volume of $130.92 \mathrm{~m}^{3}$ were used as the sample.

\section{Selection of log quality parameters}

In order to understand the importance of log quality attributes in determination of price for teak logs, this study developed a "price-quality" model using log quality attributes as independent variables and the selling price as the response variable. The selected quality attributes included the log dimensions as well as the frequently observable log defects in teak. Accordingly, the length of the log, mid circumference (under bark), diameters at the top-end and butt-end, number of knots per meter, average diameter of knots, bend fraction, percentage of heartwood, shape of the log, presence of buttress, position of the hollows, presence of felling damages, splits and heart-rot were the measured quality attributes.

Log dimension variables such as the length and mid-circumference were used in calculating the volume of a log. Other quality variables 
were selected based on the characteristics that customers pursue when selecting logs. These parameters are also specified in the Sri Lanka Standards (SLS 985:1992) for grading of timber logs.

\section{Measurement of the log quality parameters}

The logs were randomly selected and their dimensions were measured and recorded. The 'depot number' i.e. the unique number given to each $\log$ at the log storing facility was used as the identification number in recording all measurements and quality attributes of each $\log$. The data collection was carried out within three months, starting from March 2014 and ending in June 2014. This was followed by several subsequent visits to the respective storing facilities to record the selling prices of logs after they were sold through the typical auction process. Only that logs having a retention period less than six months at the storing facility were taken into consideration for further analysis. This approach was used to minimize the possible negative effects of aging/decaying on the selling price due to logs being in the yards for prolonged periods. Accordingly, the final sample included 512 logs.

The length of the log was measured using a distance tape along the straight line parallel to the central axis of the log. Mid-circumference was measured at the middle of the log underbark, using a distance tape. Diameter measurements were taken at two points; at top-end and butt-end using a distance tape. At each end, smallest and largest diameters perpendicular to each other were measured and the average diameter at each end was calculated separately. The sweep is described as the "extent which the longitudinal axis of the log deviate from a straight line" (Knoke et al. 2006). It was measured at the point of maximum deviation. The extent of the deviation was measured and expressed as a proportion of the small end diameter (Knoke et al. 2006). Two forms of bends were observed i.e. curvature in one direction and curvature in two directions. When curvature was in one direction, a rope was laid straight parallel to the log on the curved side from the center of the top-end to the center of the butt-end of the log. The distance between the rope axis and log was measured using a distance tape and the bend fraction was calculated using the Equation 1.

Bend Fraction $=\frac{\text { Deflection of bend }}{\text { Diameter of the small end of the } \log }=\frac{d}{D} \quad E q \cdot(1)$

When curvature was in two directions, the log was assumed to be bucked at the mid-point, and the two bend fractions were determined in the same manner as described above. The average bend fraction was calculated using the Equation 2 which can be further simplified as in the form of Equation 3.
The total number of knots found on each log was assessed and recorded. The clustered knots were measured as a group, while the knots having a diameter of 2 or less centimeters $(\mathrm{cm})$ were ignored. The number of knots per meter for an individual log was calculated using the Equation 4.

Number of knots per meter $=\frac{\text { Total no. of knots }}{\text { Length of the log }}$

The size of the knots was determined by measuring the knot diameter. One diameter measurement per each knot was taken for circularly shaped knots. In the case of oval shaped knots, the average of the longest and shortest diameter measurements at a right angle was taken. The average diameter of knots in a particular log was calculated using the Equation 5.

Average knot diameter $=\frac{\text { Sum of all knot diameters }}{\text { Number of knots in the log }} \quad E q \cdot(5)$

It is known that the utilizable volume of a log 
is reduced when a log has a hollow in it. The information about the position of the hollows is important when one is trying to determine the sawing pattern, aiming to maximize the lumber recovery. Generally, the hollows were observed in teak logs either at the top-end, at the middle where a branch or knot occurred, at the butt-end, at two of these positions or at all of the three positions. The position where the hollow was located in the log was recorded.

The extent of the heartwood was measured at its longest diameter in centimeters. The heartwood diameter was then compared with the diameter of the log (Knoke et al. 2006) and the heartwood percentage was calculated using the Equation 6.

Percentage of heartwood $=\frac{\text { Heartwood diameter }}{\text { Log diameter }} * 100 \%$

When assessing the shape, logs were categorized into two groups: cylindrical and nearly cylindrical (Sri Lanka Standards for grading of timber 1992). The logs showing at least $80 \%$ ratio between the shortest and the longest top end diameters were grouped as being cylindrical, while logs with $70 \%$ ratio were grouped as being nearly cylindrical. The presence of buttress was integrated as a qualitative variable that assumed two classes in the regression model: 'with buttress', 'without buttress'.

The presence of heart rot at one or both ends of a $\log$ was also considered as an important quality attribute, because the presence of heart rot severely degrades the quality of a log which ultimately leads to the formation of hollows. The presence of heart rot was included in the model by using a qualitative variable that assumed two levels: 'heart rot present' and 'heart rot absent'. The logs were visually inspected for felling damages. The logs showing such damages were classified as "with felling damages' while others were classified as 'without felling damages'. The number of logs showing splits was also recorded during the survey. The splits were integrated in the model as a qualitative variable with two classes; 'with splits' and 'without splits'.

\section{Statistical Analysis}

The collected data was analyzed by using the MS Excel 2010 and Minitab ${ }^{\circledR} 16$ statistical software. The selling prices of logs were expressed in US Dollars (USD). All the categorical variables were dummy-coded as indicated in Table 1.

\section{Model fitting}

The basic structure of a General Linear Model (GLM) was formulated between the response variable - selling price, and predictors - the quality variables (i.e. length, mid-circumEq.(6) ference, number of knots per meter, average diameter of the knots, bend fraction, percentage of heartwood, log shape, presence of buttress, position of the hollows, presence of felling damages, splits and heart rot). However, it was found that a linear regression line was not reasonable to fit the data, as the residual plot of the linear regression model showed an obvious curvature, indicating the possible quadratic behavior and the non-constant variance of data. Therefore, a logarithmic transformation of the response variable was carried out to avoid the high variability due to larger values of the response variable, an approach which is widely used in such cases (Knoke et al. 2006). The non-significant variables were removed. Correlation tests were further performed with predictor variables to identify cases of multicollinearity. The significant quality variables were tested, and then a Multiple Linear Regression (MLR) model was fitted to explain the relationship between the Log (price) and significant quality variables. The quality of the regression model was evaluated by the means of Adjusted Coefficient of Determination $\left(\mathrm{R}^{2}\right)$ and the distribution of residuals. DFFITS (difference in fit, standardized) and Cook's Distance (D) statistics were used to identify influential observations (Neter 1989) and improve 
Table 1 Coding of categorical variables

\begin{tabular}{|c|c|c|c|c|}
\hline Categorical variable & Code & No. of classes & $\mathrm{I}_{1}$ & $\mathrm{I}_{2}$ \\
\hline Average Bend fraction & & 3 & & \\
\hline Class 1: Straight log (Reference) & & & 0 & 0 \\
\hline Class 2: $(0.10-0.90)$ & $\mathrm{BF}_{\mathrm{C} 2}$ & & 1 & 0 \\
\hline Class 3: $(1.00-2.30)$ & $\mathrm{BF}_{\mathrm{C} 3}$ & & 0 & 1 \\
\hline Hollow position & & 3 & & \\
\hline Class 1: No hollow (Reference) & & & 0 & 0 \\
\hline Class 2: At top end \&/or middle & $\mathrm{HP}_{\mathrm{C} 2}$ & & 1 & 0 \\
\hline Class 3: At butt end & $\mathrm{HP}_{\mathrm{C}}$ & & 0 & 1 \\
\hline Average number of knots per meter & & 3 & & \\
\hline Class 1: (0-1.0) (Reference) & & & 0 & 0 \\
\hline Class 2: $(1.1-2.0)$ & $\mathrm{K}_{\mathrm{C} 2}$ & & 1 & 0 \\
\hline Class 3: $(2.1-5.0)$ & $\mathrm{K}_{\mathrm{C} 3}^{\mathrm{C} 2}$ & & 0 & 1 \\
\hline Log shape & & 2 & & \\
\hline Class 1: Cylindrical (Reference) & & & 1 & \\
\hline Class 2: Nearly cylindrical & $\mathrm{LS}_{\mathrm{C} 2}$ & & 0 & \\
\hline Percentage of Heartwood & & 2 & & \\
\hline Class 1: More than $75 \%$ of heartwood (Reference) & & & 1 & \\
\hline Class 2: Less than $75 \%$ of heartwood & $\mathrm{HW}_{\mathrm{C} 2}$ & & 0 & \\
\hline Presence of Buttress & & 2 & & \\
\hline Class 1: Absent (Reference) & & & 1 & \\
\hline Class 2: Present & $\mathrm{BT}_{\mathrm{C} 2}$ & & 0 & \\
\hline Presence of Heart rot & & 2 & & \\
\hline Class 1: Absent (Reference) & & & 1 & \\
\hline Class 2: Present & $\mathrm{HR}_{\mathrm{C} 2}$ & & 0 & \\
\hline Presence of Felling damage & & 2 & & \\
\hline Class 1: Absent (Reference) & & & 1 & \\
\hline Class 2: Present & $\mathrm{FD}_{\mathrm{C} 2}$ & & 0 & \\
\hline Presence of Splits & & 2 & & \\
\hline Class 1: Absent (Reference) & & & 1 & \\
\hline Class 2: Present & $\mathrm{SP}_{\mathrm{C} 2}$ & & 0 & \\
\hline
\end{tabular}

the model fit by eliminating such cases. The quality variables identified as significant in the model were subjected to a stepwise-regression in order to rank them according to their 'order of affiliation' to the price.

\section{Model Validation}

Before proceeding with model fitting, $100 \mathrm{ob}-$ servations were randomly selected and excluded from the data set to be used in model validation. In model validation, price predictions were calculated using the derived regression model for the above 100 observations and the predicted selling prices were compared with actual selling prices using a Q-Q Plot.

\section{Estimation of price reduction due to the pres- ence of defective quality attributes}

The final regression model was used to examine the impact on the selling price, when a defective quality attribute is present. In this process, fixed values were used for all variables except the variable for which the price effect needed to be examined. The effect on price was examined for a log with the dimensions of $4.3 \mathrm{~m}$ in length and $0.75 \mathrm{~m}$ in mid- 
circumference under-bark (average length and mid-circumference of logs in the sample) i.e. a $\log$ with a volume of $0.192 \mathrm{~m}^{3}$ using the formula enclosed in Equation 7.

Percentage price reduction of the timber log

$$
=\frac{\text { Price Difference }}{\text { Price of the defect free } \log } * 100 \% \quad E q \cdot(7)
$$

Price variation was expressed in terms of USD per cubic meter.

\section{Results}

\section{Basic descriptive statistics of sampled logs}

Table 2 shows the descriptive statistics of selected quality variables of the sample. Over $40 \%$ of the measured logs were between 2.1 to $4.0 \mathrm{~m}$ in length. The most frequently observed defects in the measured logs were knots, buttress, sweep (bend), and hollow. Splits, harvesting damages, and heart rot were relatively less frequent (Figure 1).

During the preliminary visits to timber auctions, it was observed that the selling prices of most of the logs often fall below the market prices, a fact that suggests that the customers are not willing to purchase logs at the advertised price as the auctioned logs often lack the customer-desired quality attributes. A comparison between the advertised price and the selling price was carried out using a paired $t$-test, and the results indicated a significant difference $(p<0.001, \alpha=0.05)$. Therefore, it can be

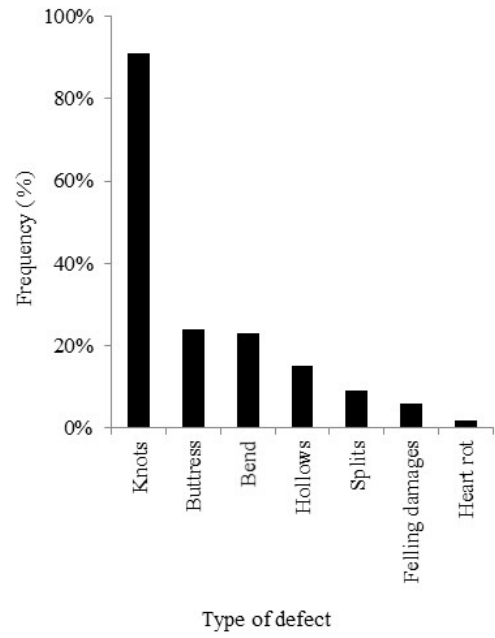

Figure 1 Frequency of occurrence of visible defects

inferred that, the prices are eventually determined by the perceived timber quality as it is visually observed by the customers.

\section{Identification of key determinants of price}

Several predictor variables i.e. length, mid-circumference, number of knots per meter, bend fraction and hollow position were found significant in the GLM. The model achieved a strong coefficient of determination $\left(R^{2}=0.87\right)$, and the statistically significant variables at $p<0.05$ level are indicated in Table 3. The sample size used for the GLM and MLR analysis were 512 teak logs as 38 observations had to be removed due to aging/decaying, while another 100 ob-

Table 2 Basic descriptive statistics of sampled logs

\begin{tabular}{lrrrrr}
\hline & Range & Mean & SE of Mean & Standard Deviation & Variance \\
\hline Price (USD) & 702.95 & 86.31 & 4.43 & 100.30 & 10059.19 \\
Length (m) & 7.60 & 4.34 & 0.08 & 1.86 & 3.44 \\
Mid-Circumference (m) & 1.10 & 0.74 & 0.01 & 0.20 & 0.04 \\
Average Bend Fraction & 2.33 & 0.11 & 0.01 & 0.24 & 0.06 \\
Heartwood percentage (\%) & 64.62 & 80.32 & 0.46 & 10.29 & 105.80 \\
No. of knots per meter & 4.90 & 1.15 & 0.04 & 0.93 & 0.86 \\
\hline
\end{tabular}


Table 3 Basic descriptive statistics of sampled logs

\begin{tabular}{lcrrrr}
\hline Source (abbreviation in parenthesis) & $D F$ & Adj. SS & Adj. $M S$ & \multicolumn{1}{l}{$p$} & $R$-Sq (adj) \\
\hline Length $(\mathrm{L})$ & 1 & 18.186 & 18.186 & $0.000^{*}$ & 0.87 \\
Mid-Circumference (MC) & 1 & 43.307 & 43.307 & $0.000^{*}$ & \\
No. of knots per meter class_2 $\left(\mathrm{K}_{\mathrm{C} 2}\right)$ & 1 & 0.093 & 0.093 & 0.091 & \\
No. of knots per meter class_3 $\left(\mathrm{K}_{\mathrm{C} 3}\right)$ & 1 & 0.638 & 0.638 & $0.000^{*}$ & \\
Bend fraction class_2 $\left(\mathrm{BF}_{\mathrm{C} 2}\right)$ & 1 & 0.028 & 0.028 & 0.354 & \\
Bend fraction class_3 $\left(\mathrm{BF}_{\mathrm{C} 3}\right)$ & 1 & 0.180 & 0.180 & $0.019^{*}$ & \\
Hollow position class_2 $\left(\mathrm{HP}_{\mathrm{C} 2}\right)$ & 1 & 0.536 & 0.536 & $0.000^{*}$ & \\
Hollow position class_3 $\left(\mathrm{HP}_{\mathrm{C} 3}\right)$ & 1 & 0.008 & 0.008 & 0.628 & \\
Log shape class_2 $\left(\mathrm{LS}_{\mathrm{C} 2}\right)$ & 1 & 0.008 & 0.008 & 0.629 & \\
Percentage of Heartwood class_2 $(\mathrm{HW}$ & 1 & 0.020 & 0.020 & 0.432 & \\
Presence of Buttress class_2 $\left(\mathrm{BT}_{\mathrm{C} 2}\right)$ & 1 & 0.082 & 0.082 & 0.111 & \\
Presence of Splits class_2 (SP $\left.{ }_{\mathrm{C} 2}\right)$ & 1 & 0.001 & 0.001 & 0.836 & \\
Presence of Felling damages class_2 $\left(\mathrm{FDc}_{2}\right)$ & 1 & 0.020 & 0.020 & 0.432 & \\
Presence of Heart rot class_2 $\left(\mathrm{HR}_{\mathrm{c} 2}\right)$ & 1 & 0.114 & 0.114 & 0.060 & \\
\hline
\end{tabular}

Note. Abbreviation: * - statistically significant at 0.05 level.

servations were set aside for model validation.

The best price-quality model obtained is expressed in Equation 8.

$\log ($ price $)=-0.053+0.121 L+1.680 M C-0.211 B F_{c 3}-0.112 K_{c 3}$ $-0.138 H P_{c 2}-0.037 B T_{c 2}-0.117 H R_{c 2} \quad$ Eq. (8)

Subsequently, the best model was fitted with only selected quality attributes enclosed in Table 4 . Accordingly, the adjusted $R^{2}$ value of the final regression model was 0.87 . According to the Equation 7, it is clear that certain classes of quality variables had a significant impact on the selling price. Thus, if the bend fraction would have been over 1.0 and number of knots per meter would have been greater than 2.1 they would cause a negative impact on the price. At the same time, the presence of a hollow at the top end or at the middle of the log as well as the presence of buttress and heart rot would have also similar detrimental effects.

Out of the 11 tested variables, 7 showed a significant influence on the selling price. Out of the four continuous independent variables, the mid-circumference and length showed a strong positive relationship with price $(p<0.001)$. The coefficient value of mid-circumference indicated a larger impact on price than the length. However, the "number of knots per meter' $(p<0.001)$, 'hollow at top end \&/or middle' $(p<0.001)$, 'bend fraction' $(p=0.021)$, 'presence of buttress' $(p=0.045)$ and 'presence of heart rot' $(p=0.034)$ indicated statistically significant negative relationships with the price as the presence of these defects can reduce the lumber recovery potential. The coefficient values of continuous variables such as the length and mid-circumference indicate the magnitude of difference in Log (price) that would occur when 1 unit of the respective variable is changed. Residual plots do not indicate any serious violations of the assumptions and hence the selected model is statistically acceptable (Figure 2).

The prices predicted using the derived regression model and the actual prices achieved/ observed were compared using a $Q-Q$ Plot that revealed very little deviation from the mean line (Figure 3).

\section{Perceived impact of quality attributes on price}

The results of the percentage reduction of price due to the presence of a specific defect char- 

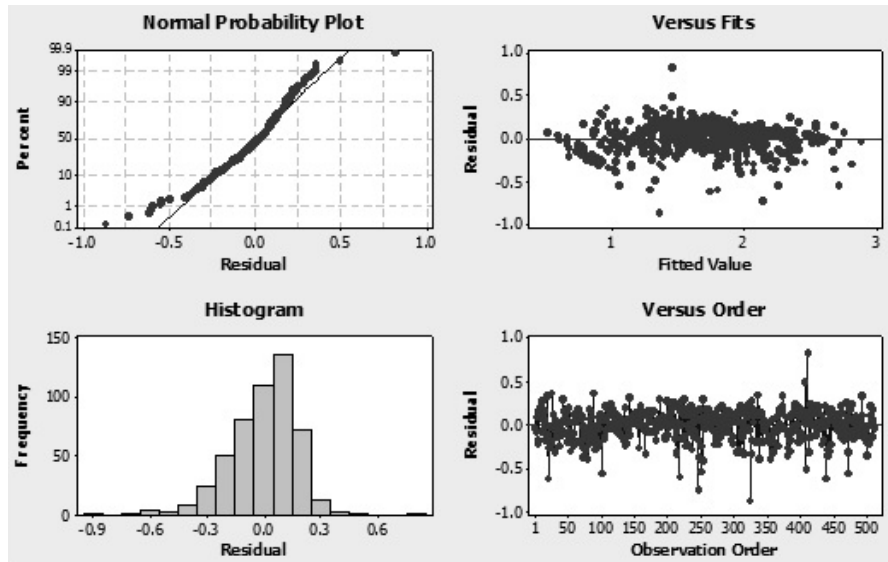

acterized by a specific level/ magnitude are given in Table 5. The highest reduction in price was due to the presence of knots $(59.97 \%)$, whereas lowest price reduction was due to the presence of buttress (8.21\%).

In addition, the price increment due to the increase of one unit of length and midcircumference were 1.32 USD and 47.86 USD respectively. Therefore, this confirms that the highest effect on price is by mid-circumference, followed by length, average number of knots per meter, bend fraction, hollow position, heart rot and buttress in the mentioned order.

\section{Discussion}

How the visually observable timber quality attributes influence the selling price is less researched, especially in the context of tropical timbers. As such, there is a general lack of information dealing with the impact of various $\log$ quality attributes on the market price. In a

Table 4 The final regression model

\begin{tabular}{lllllll}
\hline Dependent & Predictor & Coefficient & $\begin{array}{l}\text { Standard Error } \\
\text { of Coefficient }\end{array}$ & $p$ & $\begin{array}{l}R-S q \text {. } \\
\text { (adj.) }\end{array}$ & $\begin{array}{l}\text { Sum of } \\
\text { Square } \\
\text { Residual } \\
\text { Error }\end{array}$ \\
\hline Log(price) & & & & & & \\
& Constant & -0.053 & 0.036 & 0.136 & 0.87 & 16.242 \\
& Length & 0.121 & 0.005 & $0.000^{*}$ & & \\
& Mid-Girth & 1.680 & 0.044 & $0.000^{*}$ & & \\
& $\begin{array}{l}\text { Bend fraction } \\
\text { (1.0-2.3) }\end{array}$ & -0.211 & 0.091 & $0.021^{*}$ & & \\
& $\begin{array}{l}\text { No. of knots per } \\
\text { meter (2.1-5.0) }\end{array}$ & -0.112 & 0.024 & $0.000^{*}$ & & \\
& $\begin{array}{l}\text { Hollow at top end } \\
\text { \&/or middle }\end{array}$ & -0.138 & 0.032 & $0.000^{*}$ & & \\
Buttress & -0.037 & 0.019 & $0.045^{*}$ & & \\
& Heart rot & -0.117 & 0.055 & $0.034^{*}$ & & \\
\hline
\end{tabular}

Note. Abbreviation: * - statistically significant at 0.05 level. 
Table 5 Percentage reduction of price due to the presence of a specific defect characterized by a specific level/magnitude

\begin{tabular}{lllll}
\hline Log quality variable & $\begin{array}{l}\text { Price of a } \\
\text { defect free } \\
\log (\mathrm{USD})\end{array}$ & $\begin{array}{l}\text { Price with } \\
\text { defect (USD) }\end{array}$ & $\begin{array}{l}\text { Price difference } \\
\left(\mathrm{USD} / \mathrm{m}^{3}\right)\end{array}$ & $\begin{array}{l}\text { Percentage } \\
\text { price change }\end{array}$ \\
\hline $\begin{array}{l}\text { Hollow position } \\
\text { Class 2: At top end and/or middle }\end{array}$ & 53.36 & 38.84 & 14.52 & $27.21 \%$ \\
$\begin{array}{l}\text { Presence of buttress } \\
\text { Class 2: Present }\end{array}$ & 53.36 & 48.98 & 4.38 & $8.21 \%$ \\
$\begin{array}{l}\text { Average bend fraction } \\
\quad \text { Class 3: }(1.0-2.3)\end{array}$ & 53.36 & 23.94 & 29.42 & $55.13 \%$ \\
$\begin{array}{l}\text { Average no. of knots per meter } \\
\quad \text { Class 3: }(2.1-5.0)\end{array}$ & 53.36 & 21.36 & 32.00 & $59.97 \%$ \\
$\begin{array}{l}\text { Heart rot } \\
\text { Class 2: Present }\end{array}$ & 53.36 & 40.76 & 12.60 & $23.61 \%$ \\
\hline
\end{tabular}

Note. Prices are based on the currency exchange rates as of June 2015: 1 USD $=132$ LKR

study that aimed to explain the buyers' preference for high quality beech timber, Knoke et al. (2006) found red heartwood, stem curvature, spiral grain, growth stresses and roughness of the bark as important quality attributes affecting the customer preference. Reddy and Bush (1998) used a conjoint analysis approach to identify the buyers' perceptions on softwood lumber values. However, in Reddy and Bush (1998)'s work, they used the timber price as an independent variable affecting the value that timber buyers place on a specific log. In this study, the price was used as the response variable. This approach is also known as the hedonic pricing, which is a statistical method of explaining the price behavior relative to the internal characteristics of the goods (Le Goffe 2000).

The accuracy of a regression model is often expressed in terms of coefficient of determination $\left(R^{2}\right)$ and residual distribution plots which can be easily compared. However, a regression model cannot be considered as being robust based solely on the fact that the model is having higher $R^{2}$ (Neter 1989). The logarithmic transformation used during the model development process has improved the $R^{2}$. Conversely, the 114 logarithmic transformation limits the practical applicability of the model as the estimates for the expected prices would be biased because the average of real estimation errors is positive. After fitting a linear regression model, it was observed that the residual plot is indicating a possible quadratic behavior and non-constant variance of data. Therefore, logarithmic transformation of price was performed to overcome this situation (Knoke et al. 2006).

The price-quality model developed by Knoke et al. (2006) for high quality beech timber achieved an overall $\mathrm{R}^{2}$ of 0.66 . By comparison, this study achieved a statistically more robust model. However, the rationale behind the model structure and the selection of predictor variables is of greater importance than model accuracy measures in this type of studies. At least from this point of view, the model developed in this study can be justified as all the independent variables included in the model are used as quality measures in log grading. The signs of all parameters are realistic i.e. length and mid-circumference with positive coefficients while log defects having negative coefficients. Moreover, it is obvious that different buyers would evaluate the same log differently 
based on the intended end-use. This could be one of the reasons for which the chosen predictors failed to fully explain the price dispersion.

Despite being able to develop a robust model that explains the impact of quality attributes on price, this study has its own limitations. Fresh teak logs are often preferred by customers. Colour of the heartwood is also an aesthetically important attribute that is highly associated with the end-use and price (Thulasidas \& Bhat 2006). As cut-ends of logs easily get discolored over time, such quality attributes were difficult to evaluate at the time the study was carried out. Furthermore, teak is highly demanded at present in the local market. This may increase the tolerance levels of timber buyers towards certain quality constraints present in logs.

The study may be further affected by limitations such as the shorter data collection period, and the measured logs not representing the entire growing stock. The time lag between harvesting and transporting to the storage facility could not be verified, and the logs could undergo different conditions that can affect their overall quality. Along with its price predicting capability, the model developed in the present study also reveals key visually observable quality attributes used by customers in evaluating the teak logs. The lack of appropriate silvicultural practices in home-garden and plantation forestry often result in producing defective teak logs with less market value (Thulasidas $\&$ Bhat 2009). As such, knowledge on the customer-desired quality attributes of teak logs at the market place would further enable forest managers to make informed decisions in teak plantation management. Therefore, this study provides a less time and resources consuming approach for developing standards, considering the intended end use.

It was further observed that the selling prices of teak logs often fall below the advertised prices, a fact that suggests that the customers are not willing to purchase logs at the advertised price. This may be due to auctioned logs lacking the customer-desired quality attributes or advertised price being too high. The findings and the approach presented in this study may be helpful in developing realistic pricing strategies for teak logs.

\section{Conclusions}

This study aimed to express the relationship between the selling price and some selected quality attributes of teak logs. The study findings suggest that the ultimate selling price of teak logs is determined by the customer's subjective evaluation of the log quality, which is assessed using visually observable characteristics such as the log dimensions and visible defects. In addition to log dimensions, the number of knots, hollow position, bend fraction, presence of buttress and presence of heart rot were found to be the key quality attributes that customers are most concerned, and therefore they can be identified as important key determinants of the selling price for teak logs. According to the derived price-quality model in this study, the presence of high number of knots had the highest detrimental impact on price, followed by higher bend fraction, presence of hollows at top end and/or middle of the $\log$, presence of heart rot and presence of buttresses. On the other hand, the increase in midcircumference of a log seems to have a stronger positive influence on the selling price than that of increasing length of the log. The study findings have further implications in teak forests management. As the key determinants of the price for teak logs have been identified, forest managers would be able to develop adequate teak management strategies.

\section{Acknowledgements}

The authors wish to acknowledge the Research Grant Scheme of the University of Sri Jayewardenepura (Res. Grant: ASP/06/RE/ $\mathrm{SCI} / 2012 / 05$ ) for funding this project, and the anonymous reviewers for their suggestions to 
substantially improve the manuscript.

\section{References}

Amarasekara H.S., 1996. Alternative timber species-A review of their properties and uses. Forestry for development. Proceedings of the Annual Forestry Symposium 1995, pp. 76-85

Amarasekara H.S., 1997. Selecting alternatives in place of naturally grown timber species. Local timbers for future? http://dl.sjp.ac.lk/dspace/bitstream/123456789/355/1. Accessed 08 May 2014

Chernyh M., Kargashina E., Štollmann V., 2013. Assessing the impact of aesthetic properties on wood characteristics decorativeness. Acta Facultatis Xylologiae Zvolen - The Scientific Journal of the Faculty of Wood Sciences and Technology 55(1): 21-26

Gligoraş D., Borz S. A., 2015. Factors affecting the effective time consumption, wood recovery and feeding speed when manufacturing lumber using a FBO-02 CUT mobile bandsaw. Wood Research 60 (2): 329-338

Ivković, M., Wu, H. X., Spencer, D. J., McRae, T. A., 2007. Modelling the effects of stem sweep, branch size and wood stiffness of radiata pine on structural timber production. Australian Forestry 70(3): 173-184. DOI: 10.1080/00049158.2007.10675018

Knoke T., Stang S., Remler N., Seifert T., 2006. Ranking the importance of quality variables for the price of high quality beech timber (Fagus sylvatica L.). Annals of Forest Science 63:399-413. DOI: 10.1051/forest:2006020

Le Goffe P., 2000. Hedonic Pricing of Agriculture and Forestry Externalities. Environmental and Resource Economics 15(4): 397-401. DOI: 10.1023/ A:1008383920586

Ministry of Forests, Lands and NRO, British Columbia, 2011. Timber grading: Scaling Manual. https://www. for.gov.bc.ca/ftp/hva/external/!publish/Web/Manuals/
Scaling/chapters/Ch8.pdf. Accessed on 20 April 2014

Neter J., Wasserman W., Kutner M.H., 1989. Applied linear regression models. Second Edition. Richard D. Irwin, Boston, $667 \mathrm{p}$.

Perera P.K.P., Vlosky R.P., Amarasekera H.S., De Silva N., 2006. Forest certification in Sri Lanka. Forest Products Journal 56(11/12): 5-11

Perera P.K.P., Amarasekera H.S., Weerawardena N.D.R., 2012. Effect of growth rate on wood specific gravity of three alternative timber species in Sri Lanka: Swietenia macrophylla, Khaya senegalensis and Paulownia fortune. Journal of Tropical Forestry and Environment 2(1):26-35

Reddy V.S., Bush R.J., 1998. Measuring softwood lumber value: A conjoint analysis approach. Forest Science 44 (1): $145-157$

Riekkinen M., Lukkarinen A., Lindström H., Verkasalo E., 2004. Timber assortments and selected aesthetic wood properties of Nordic Scots pine (Pinus sylvestris L.). Proceedings of Forestry Woodchain Conference, Edinburgh 28-30 September 2004.

Ruwanpathirana N.D., 2014. Development of a timber property classification based on the end-use with reference to twenty Sri Lankan timber species. Journal of Tropical Forestry and Environment 4(1):1-13

Sri Lanka Standards Institution. 1992. Sri Lanka standard for grading of timber. Part 3: Grading of logs, SLS pp. 985:1992

Thulasidas P.K., Bhat K.M., 2006. Heartwood colour variation in home garden Teak (Tectona grandis) from wet and dry localities of Kerala, India. Journal of Tropical Forest Science 18(1): 51-54

Thulasidas P.K., Bhat K.M., 2009. Log characteristics and sawn timber recovery of home-garden Teak from wet and dry localities of Kerala, India. Small-scale Forestry 8(1): 15-24. DOI: $10.1007 / \mathrm{s} 11842-008-9064-0$

Weerasinghe D.P., 2009. Comparison of wood quality of even aged Teak (Tectona grandis L.f.) plantations in three districts of Sri Lanka. Dissertation. University of Sri Jayewardenepura, Sri Lanka. 